Cuadernos de Filología Italiana

ISSN: 1133-9527

https://dx.doi.org/10.5209/cfit.58806

\title{
Milán en llamas. La ciudad modernista en el relato L'incendio di via Keplero de Carlo Emilio Gadda
}

\author{
Marta Tutone ${ }^{1}$
}

Recibido: 05 de febrero de 2018 / Modificado: 04 de enero de 2019 / Aceptado: 05 de abril de 2019

Resumen. El artículo propone una reflexión sobre las instancias modernistas presentes en el relato L'incendio di via Keplero de Carlo Emilio Gadda a partir de la metrópoli como elemento diegético central en la narración. Se pondrá especial énfasis en las técnicas narrativas que tienen algún punto de contacto con el montaje cinematográfico vanguardista de principios del siglo XX.

Palabras clave: Gadda, modernismo, metrópoli, via Keplero.

[en] Milan's burning. The Modernist city in the short story L'incendio di via Keplero by Carlo Emilio Gadda

\begin{abstract}
This paper proposes a reflexion about modenist's elements in the short story L'incendio di via Keplero by Carlo Emilio Gadda. The metropoli becomes a diegetic nerve centre of the narration. The article highlights the connection between the narrative technique and the avant-garde cinematographic editing of the beginning of 20th century.
\end{abstract}

Keywords: Gadda, modernism, metropolis, via Keplero.

Cómo citar: Tutone, Marta (2019): «Milán en llamas. La ciudad modernista en el relato L'incendio di via Keplero de Carlo Emilio Gadda», Cuadernos de Filología Italiana, 26, pp. 245-259.

La ciudad moderna, con su babélica expansión frente al silencio de los monumentos como única memoria del pasado, enmarca la crisis de la civilización a comienzos del siglo XX vaticinada por el arte y las literaturas vanguardistas europeas. La metrópoli, organismo prolífico impulsado por la energía de las máquinas, fagocita la historia y reescribe el imaginario hasta convertirse, en algunos casos, en un lugar de la mente, una distopía. Me gustaría delinear algunos aspectos del relato L'incendio di via Keplero que lo conectan con las sensibilidades y las restantes escrituras europeas del mismo período; Milán, no menos que Londres, Dublín, París, Viena o Moscú en las grandes novelas modernistas, es la encrucijada en la que se despliega el relato objeto de estudio.

\footnotetext{
1 Universidad Complutense de Madrid, Calle Arganzuela 29 D ático B, ES-28005 Madrid. mtutone@ucm.es.
} 
La relación con su ciudad natal es para Gadda un terreno de ambivalencias muy fértil para su escritura. Gadda es profundamente milanés, en primer lugar, porque su escritura hace hincapié siempre en lo que conoce, antes de desdoblarse, un paso después, en múltiples caminos que se insinúan hacia el núcleo del dato real y que, al alejarse de él, dejan rastros que se confunden entre sí. Mapas, ya no de la ciudad, sino de su forma de conocerla y de recordarla literariamente. Si queremos movernos en la ciudad de Gadda tenemos que ponernos las lentes focales de la narración y mirar, antes que al tejido urbano, al entramado de las palabras. A veces la exuberante sintaxis de sus períodos deja sitio a la parataxis, pasando del enredo a la yuxtaposición de cuadros que nos hacen sospechar que la distancia se acorta vertiginosamente y que nos estamos adentrando hasta tal punto en la maraña que no tenemos la visión de la complejidad, que no podemos distinguir las relaciones, los lazos entre los elementos, sino tan solo segmentos de esa realidad. Se trata de un zoom poderoso que se pone en marcha cuando el escritor quiere mostrarnos esos cuadros del interior de las casas, los teatros, los museos, donde actúan como por inercia la aristocracia y la burguesía milanesas. La hostilidad de Milán es proporcional a la estrechez de miras de la burguesía, a la que Gadda contrapone una visión deformante y arrolladora; desde los techos a las calles, pasando por los más mínimos detalles domésticos ${ }^{2}$.

El argumento del relato objeto de estudio se inspira en un suceso real: un incendio, de causas desconocidas, que ocurrió en 1929 y en el que perdieron la vida tres personas. El dramático acontecimiento tuvo lugar en la calle Antonio Boltraffio, a poco más de un kilómetro de la calle Keplero, en la zona de la estación de trenes de Milán, un barrio popular de heterogéneos habitantes. Resulta significativo el desplazamiento ficcional de una calle dedicada a un pintor renacentista milanés a otra que lleva el nombre del astrónomo y matemático alemán Johannes Kepler, quien descubrió las leyes que regulan el movimiento de los planetas y sugirió la idea de una armonía celeste cuyas manifestaciones se podrían reconocer incluso en la composición musical.

En L'incendio di via Keplero, Gadda manipula un calamitoso acontecimiento dando cuerpo a una narración que avanza por cuadros sinópticos: de la calle desde la que vemos llegar el camión de bomberos, al interior del edificio en llamas, subiendo piso tras piso antes de volver a bajar y perderse en una panorámica urbana. La descripción de la evacuación sigue el movimiento ascensional de las llamas. Cinco cuadros del interior retratan la toma de conciencia del peligro y la consiguiente fuga, escaleras abajo, de los inquilinos de la calle Keplero. Todo ocurre a la vez: la pequeña Flora Procopio de tres años es rescatada por el ex-reo Achille Besozzi, vecino de la planta de arriba, donde vive en alquiler en casa de la señora Fumagalli; el mozo de la estación, Pedroni, bajando del apartamento de su amante en el tercer piso, salva a

2 En este sentido una de las obras más emblemática es L'Adalgisa donde el autor retrata en diez «disegni», bocetos, lienzos, a la burguesía milanesa. El escritor nos ofrece, de hecho, una sucesión de cuadros, es decir, segmentos de la dimensión urbana de una sociedad incapaz de generar una narración orgánica, y mucho menos una epopeya, y cuyos lazos no son las responsabilidades sociales y políticas que la élite debería asumir en una época de cambios, sino la mera pertenencia de clase, postales de un mundo anquilosado, diapositivas domésticas. Observa Cenati (2010: 34) que la propia incapacidad de evolucionar de la Milán de L'Adalgisa es la cifra histórica de sus habitantes, puesto que el elemento cohesivo de la identidad colectiva se deshace progresivamente bajo los golpes de una modernidad cada vez más apremiante; el cuadro irónico dibujado por Gadda es un retrato funerario de la burguesía milanesa cuya falta de ética sofoca las mejores individualidades, las que podrían hacerse cargo de los valores colectivos y a las que, en cambio, es negada cualquier forma de evolución. 
una embarazada que se encuentra desmayada en el segundo; más arriba, en la cuarta planta, los gritos de desesperación de la señora Maldifassi serán escuchados por el joven empleado que se estaba ocupando del mantenimiento del techo del edificio, que rápidamente acude en su auxilio. El chico, una vez abajo, tendrá que volver a subir hasta el quinto piso para librar de las llamas al anciano ex-garibaldino Garbagnati y entregarlo a la ambulancia que se lo llevará a la carrera.

Todo acontece en tres minutos y simultáneamente:

Se ne raccontavano di cotte e di crude sul fuoco del numero 14. Ma la verità è che neppur Sua Eccellenza Filippo Tommaso Marinetti avrebbe potuto simultanare quel che accadde, in tre minuti, dentro la ululante topaia, come subito invece gli riuscì fatto al fuoco (Gadda 2011: 100).

El íncipit del relato hace referencia al portavoz del futurismo - cuyos conceptos clave fueron la velocidad y la simultaneidad - con un neologismo «simultanare», que anticipa la instancia visual de la narración. Un relato en el que el accidente estalla arrastrando, a ritmo de evacuación, el microcosmos de los inquilinos y los microrrelatos de sus vivencias:

La minuzia del viavai condominiale e gli squarci geopolitici più esotici, il dettaglio domiciliare della vita quotidiana e l'evento notabile di portata storica, si trovano tutti rimescolati assai ragionatamente per causa dell'incendio: che fa di via Keplero un concentrato dell'universo milanese e italiano otto-novecentesco, animato da continui sbalzi tra la contingenza sconvolta dell'accidente e coordinate spaziotemporali affatto remote (Cenati 2011: 172).

El incendio que arrasa el número 14 de la calle Keplero y el rescate de los personajes que se encontraban en el edificio dura tres minutos, y restringe a un hic et nunc la visión. Acerca, pues, al lector, más que a un punto cartesiano en la topografía de la ciudad, a un «groviglio», es decir, a una maraña de detalles que le dan la ilusión de que una visión microscópica, la del interior del edificio, pueda proporcionar una imagen más precisa, cuando no es más que otro mecanismo de deformación en acto en el texto gaddiano.

El tiempo y el espacio se funden en cada dato de la enumeración. Donnarumma (2006: 46-47), en un ensayo sobre los rasgos modernistas de cierta escritura gaddiana, habla de una narración por causas, en la que a la multiplicación de las causas correspondería la atribución de una dimensión espacial. El estudioso observa que ya Hume había afirmado que el terreno pertinente de la narración según una sucesión de causas no es tanto la ficción como la historiografía, y sugiere una lectura, que todavía no se ha llevado a cabo, de las obras de Gadda como narraciones historiográficas. Se me ocurre que, tal vez, L'incendio di via Keplero sea un texto especialmente adecuado para que pueda leerse como la historiografía a la manera gaddiana de un dramático suceso.

Gadda rompe la cadena causal enumerando un conjunto de concausas que determinan el avance simultáneo de historias dentro del mismo relato que interfieren mutuamente en el desarrollo del mismo. Se trata de un rápido montaje, casi cinematográfico, que nos recuerda las escenografías zigzagueantes de El gabinete del Doctor Caligari de Robert Weine (1920) (v. Figura 1): 

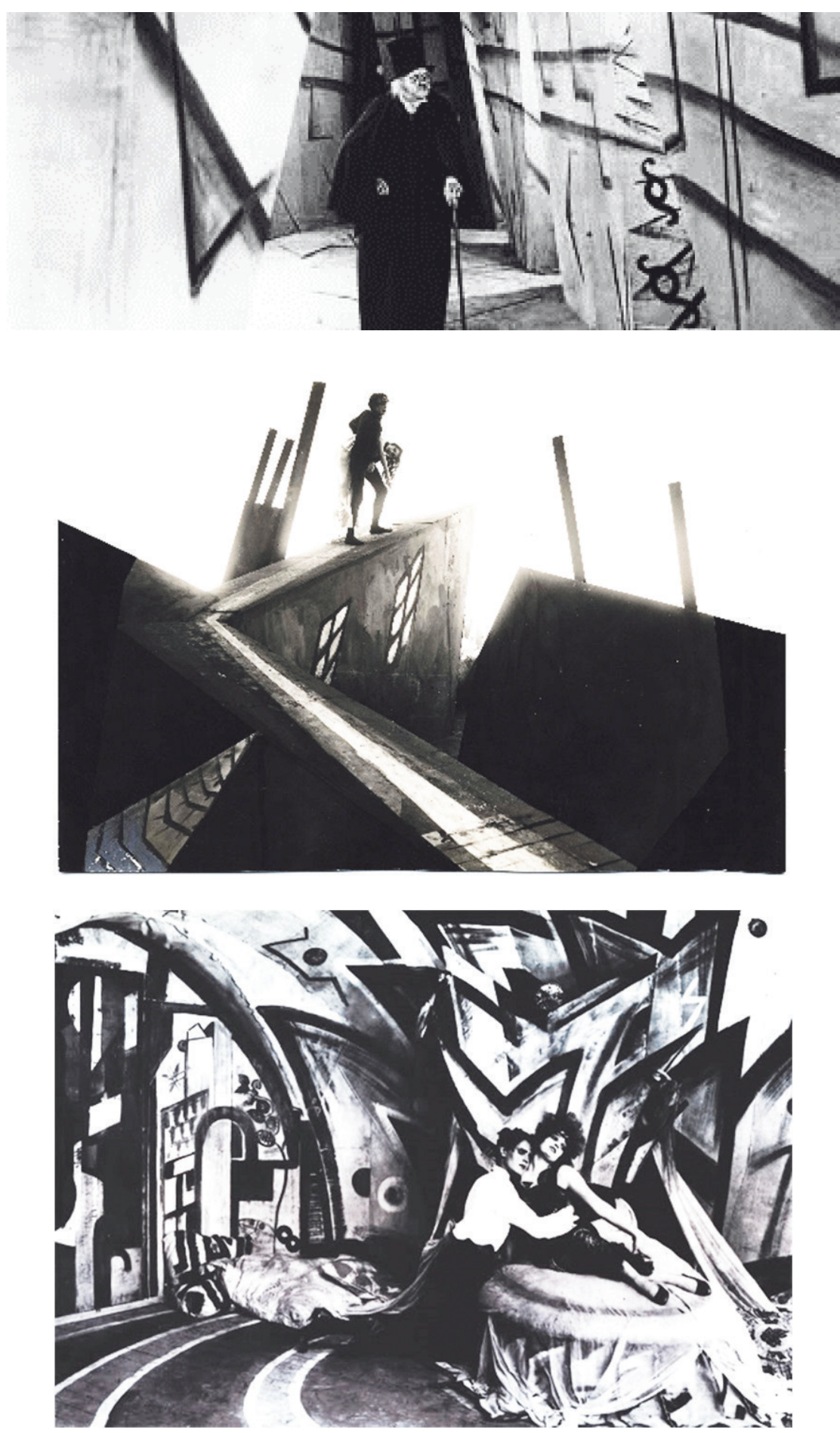

Figura 1. Algunas escenas de El gabinete del Doctor Caligari de Robert Weine (1920). 
o los decorados futuristas que diseñó el artista Enrico Prampolini para Thaïs de Anton Giulio Bragaglia (1917) (v. Figura 2):
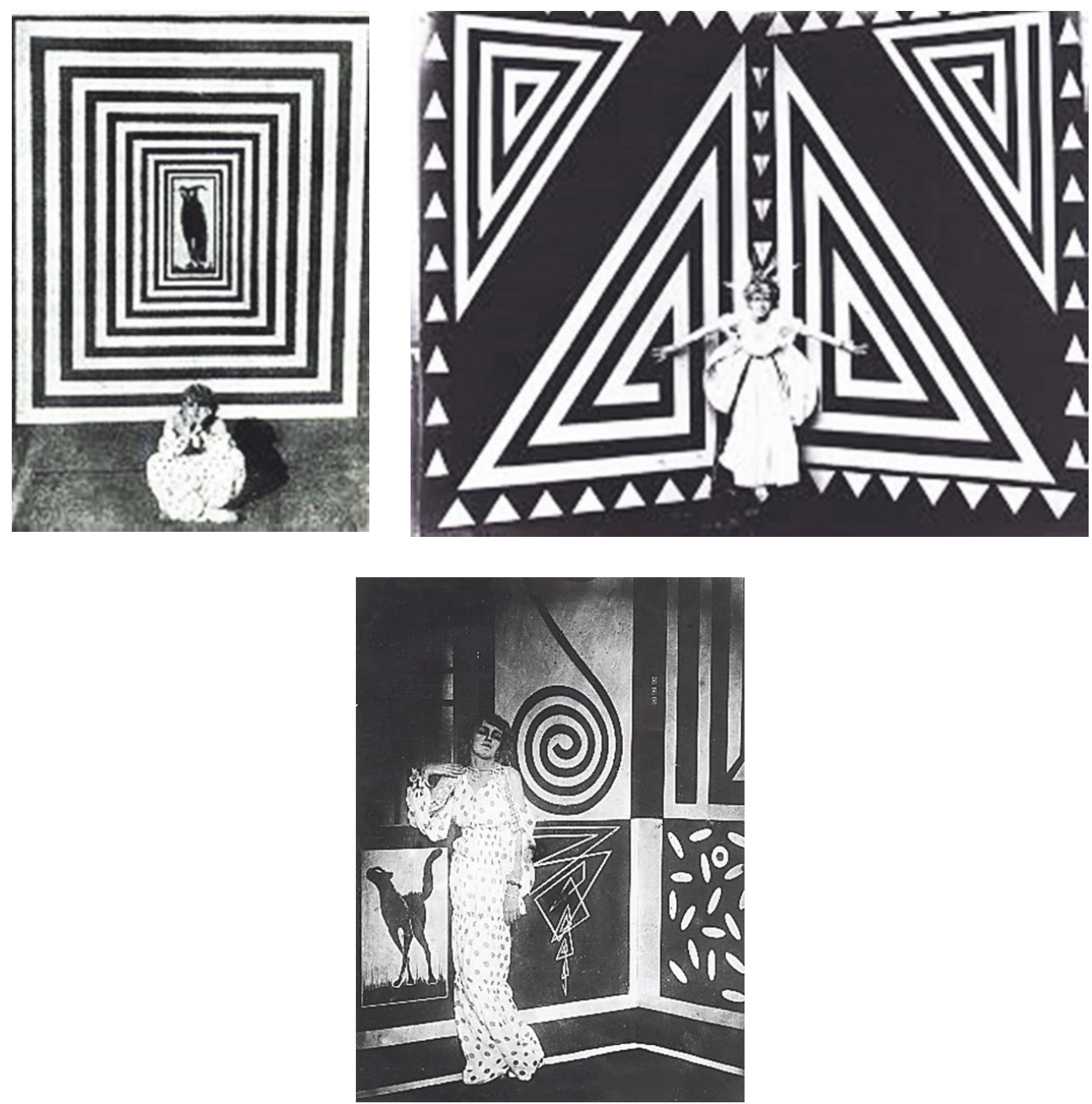

Figura 2. Algunas imágenes de los decorados de la película Thaïs de Anton Giulio Bragaglia (1917).

y, cómo no, la distopía de Fritz Lang, que en su Metrópolis (1927) utiliza la técnica del stop motion, en la que se graba la película fotograma por fotograma, y de exposición múltiple, donde en una misma escena se superponían imágenes distintas (v. Figuras 3-5). 

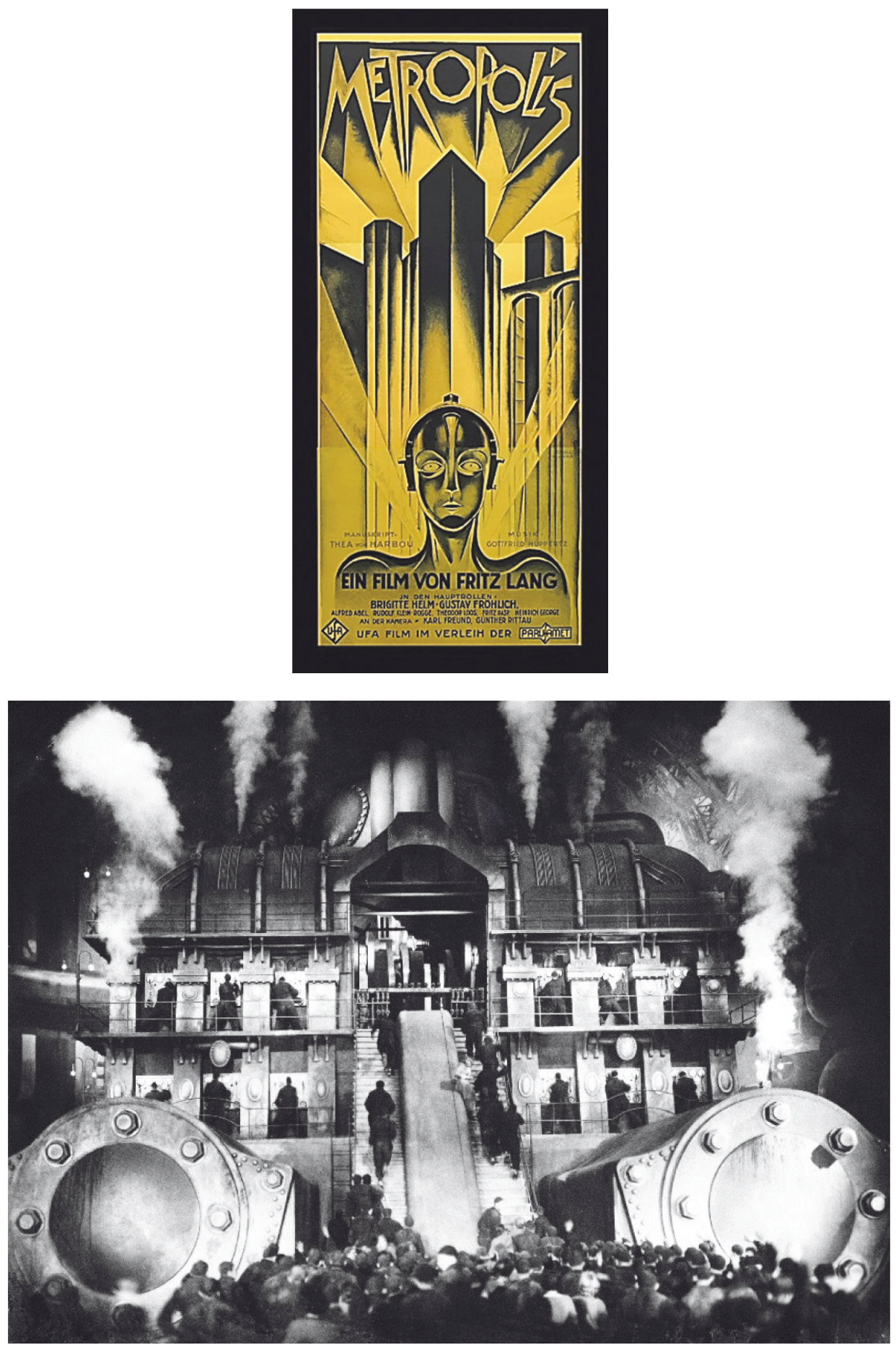

Figura 3. El cartel original de Metrópolis (1927) y una imagen del mundo retratado en la película. 


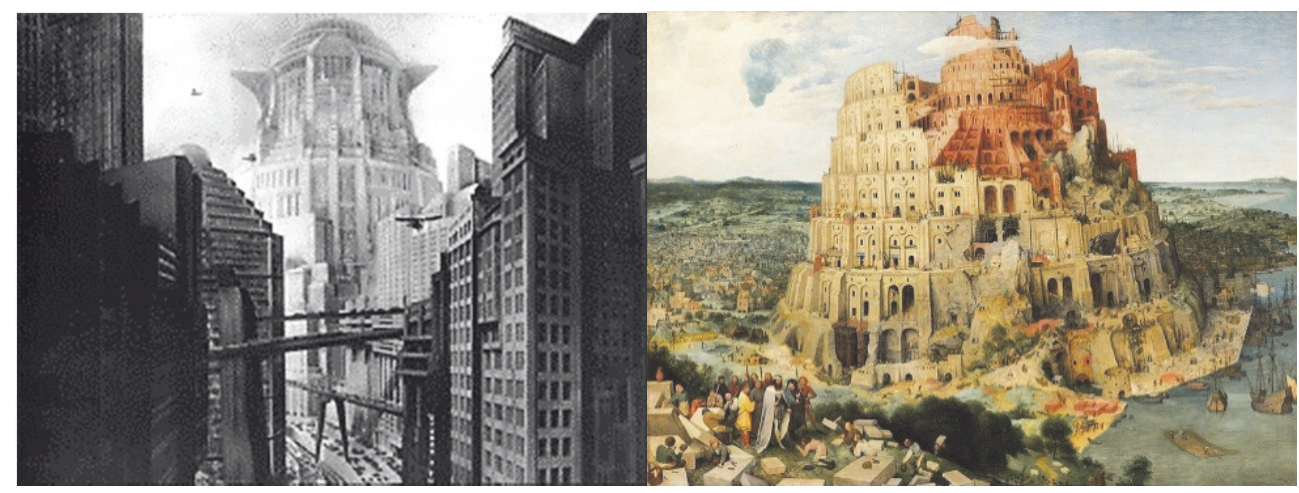

Figura 4. La torre de Metrópolis y la Torre de Babel de Pieter Bruegel (1563).

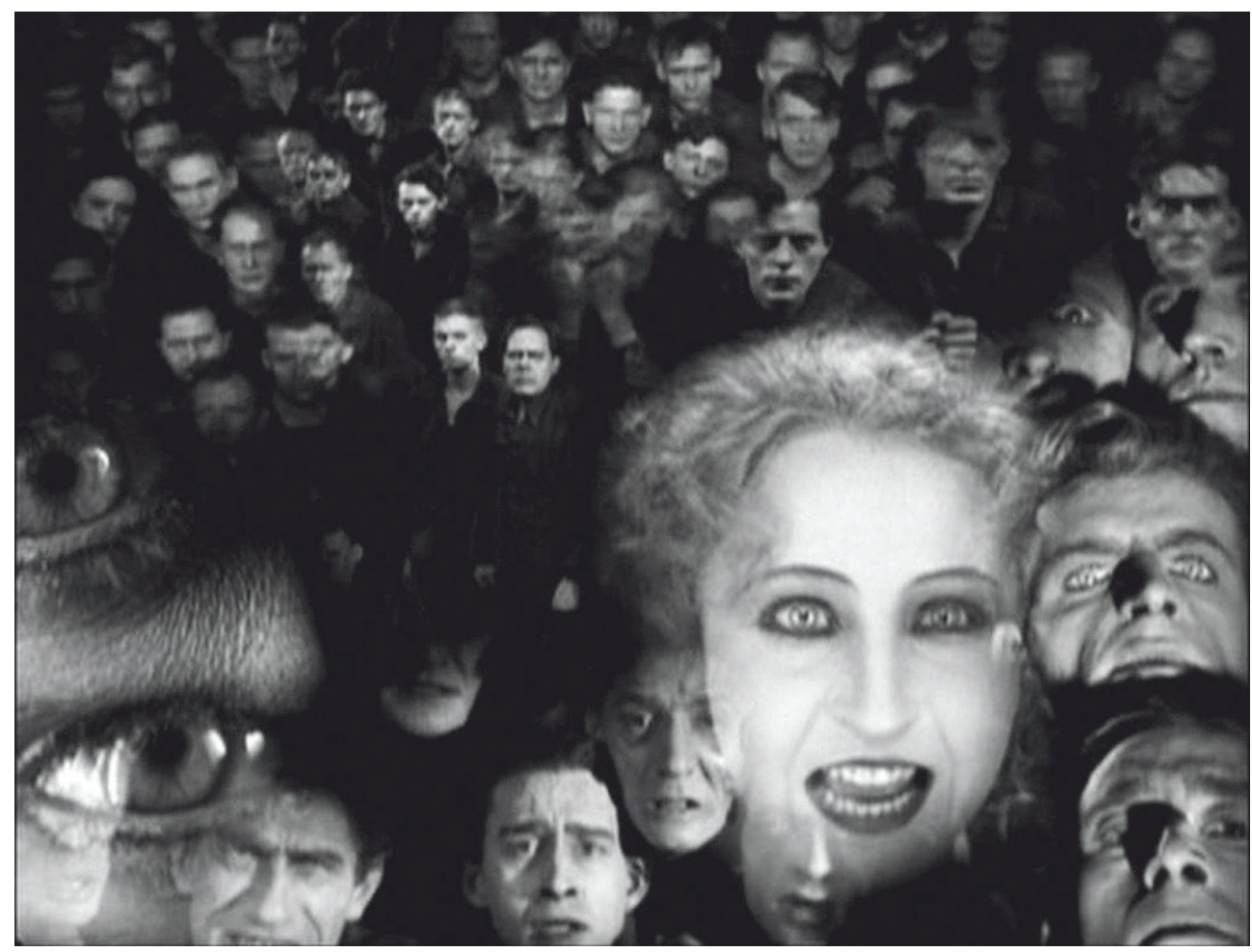

Figura 5. Un fotograma en el que puede apreciarse el uso de la técnica de grabación con exposición múltiple.

A la denuncia modernista del desasosiego causado por la modernidad, Gadda une su voz sin buscar una alteridad utópica, pues no pierde su interés en los avances 
científicos que la modernización conlleva ${ }^{3}$. Sin embargo, la ciudad, ya a finales del siglo XIX, no representaba solo el espacio, sino el tiempo. Un tiempo urbano donde la experiencia no se mide igual que la acción.

Si nos remitimos a los modelos del modernismo anglófono, podemos observar cómo ya en las novelas de Henry James el tiempo de la experiencia estética no busca un contra-altar bucólico. Londres es el lugar de lo múltiple y la arquitectura metropolitana es el símbolo de la creatividad que incide en la realidad. Sin embargo, el sujeto urbano que construye su conciencia sincronizándola con el tiempo de la experiencia interior, al amparo de las tertulias del mundo aristocrático, no resistirá mucho a la amenaza de la disgregación que fragmenta la memoria en una efímera colección de momentos inconexos. Escribir la ciudad es dar forma a una personal selección extrapolada del caleidoscopio de imágenes que esta genera, tanto de la violenta contemporaneidad como de los silentes vestigios del pasado. Y si el verdadero tiempo de la interioridad estética se reduce a una coexistencia de reliquias en el altar de la conciencia y el verdadero pasado solo se puede contemplar en los museos -observa Villa (1991: 485)-, al sujeto disgregado por la presión del ambiente urbano que no acepte abandonarse a la metrópoli futurista del desquiciamiento de las formas sintéticas y de la simultaneidad (v. Figura 6) no le queda más remedio que abandonarse a la melancolía. El James maduro del relato In the cage (1898) llegará a relegar la conciencia del individuo a la contemplación de una ciudad-texto, puesto que la protagonista es una telefonista constantemente expuesta al flujo de unas conversaciones que, separadas de la dimensión física de los interlocutores, permanecen como códigos que invitan a su desciframiento. Para llevar a la escritura la idea de la necesidad de la interpretación de la realidad desde la conciencia de la marginalidad del individuo, James elige el filtro de la tercera persona narrativa ${ }^{4}$.

En el Ulysses de James Joyce, interioridad y exterioridad llegan a coincidir y a los recovecos del alma corresponden las intricadas calles del laberinto metropolitano. El stream of cosciusness, a pesar de su matriz introspectiva -afirma Cianci (1991: 495)es inseparable de la experiencia urbana. Dublín es el lugar de la multiplicidad, de la discontinuidad, de la simultaneidad y de la superposición. «Wandering rocks», el décimo capítulo, en la parte central de la famosa novela, es una prueba de la destrucción del monolingüismo, puesto que los episodios narrados se superponen en analogía con su simultaneidad pues todos transcurren al mismo tiempo: «abolito il tempo, o meglio consentendogli di essere colto solo simultaneamente per circa un'ora, la

3 Posiblemente esa sea una peculiaridad de nuestro autor, considerando que, como afirma Donnarumma (2006:16): «Gadda condivide tutte le idee fisse del modernismo estetico: il rapporto critico con la tradizione, da un lato idoleggiata nei suoi massimi "autores", dall'altro parodiata, decostruita e sbugiardata; la riappropriazione e il ripudio dell'eredità dei padri, nella fattispecie naturalisti, simbolisti e carducciano-dannunziani; il costeggiamento dell'avanguardia, che va da una ricorrente curiosità per il futurismo a un espressionismo spontaneo; un rapporto difficile con il pubblico, cui si chiede riconoscimento mentre lo si spiazza o, peggio, lo si sbeffeggia; una dialettica irrisolta tra autoriflessività e spinte realistiche; l'ansia teorica che lo ha condotto, non solo a formulare dichiarazioni di poetica folgoranti, ma a cercare un'intersezione fra letteratura, filosofia e scienze meno armonica di quanto si creda; la demolizione di nozioni viete, come quelle di soggetto concluso e perfetto; l'impossibilità di conciliare la tensione alla totalità con la percezione di un mondo fratturato; il mito di una profondità da attingere con un faticoso lavoro di scavo e di pulizia dalle incrostazioni della falsa coscienza; una ricerca di senso aperta, mai pacificata, e perciò spesso destinata ad attestarsi sul non-detto».

4 Desde el íncipit del relato, en la traducción española de Gema Moral Bartolomé (2015: 12), apreciamos el sentimiento de rescate de la marginalidad por medio de la lectura de los códigos que proliferan en la metrópoli: «Desde un principio se le había ocurrido que en su posición, la de una joven que llevaba la vida de un conejillo de Indias o de una urraca en su confinamiento de madera y tela metálica, se relacionaría con muchas personas que no admitirían que la conocían». 
città trionfa in tutta la sua spazialità» (Cianci 1991: 496). El lector, inmerso en una galería de imágenes, puede moverse entre ellas guiándose solo por su interpretación. El autor no puede evitar que el lector se pierda y la comprensión se ve amenazada por momentos. El escritor italiano Gianni Celati, en la nota que introduce su traducción del Ulysses al italiano, se pregunta si, además de las imágenes, no será precisamente la música, ese canturreo de fondo que la escritura atrapa como si fuera una partitura musical, la que nos dé la medida de la vida que fluye en las cosas sin importancia, nimias y repetitivas. Tal vez podríamos pensar en otra fragmentación, la de la dimensión coral de la referencia épica, convertida en una impersonal cantinela de fondo, común a todos y a nadie; como las muchas versiones (murmullos, cuchicheos) de los sucesos de la calle Keplero que, afirma el autor, proliferaban entre la gente: «Se ne raccontavano di cotte e di crude sul fuoco del numero 14».

Las voces se entrelazan sin armonizarse en el poema de la modernidad. Las calles se vacían en la ciudad de Eliot, The Waste Land, y por ellas el poeta deambula. El Londres vanidoso con sus secuencias cinematográficas (como Pound definirá las escenas del poema) parece una proyección de la negligencia de sus habitantes; así como la imagen del sistema nervioso, proyectado por medio de una linterna mágica en una pantalla, en la «Love song», recuerda el laberíntico tejido urbano.

Londres es el centro del universo narrativo de Virginia Woolf, alternándose las escenas exteriores y los espacios interiores; visiones de una narradora a veces en vuelo sobre la ciudad, a veces asomada a una ventana, punto privilegiado de observación que enmarca la realidad desde un espacio seguro.
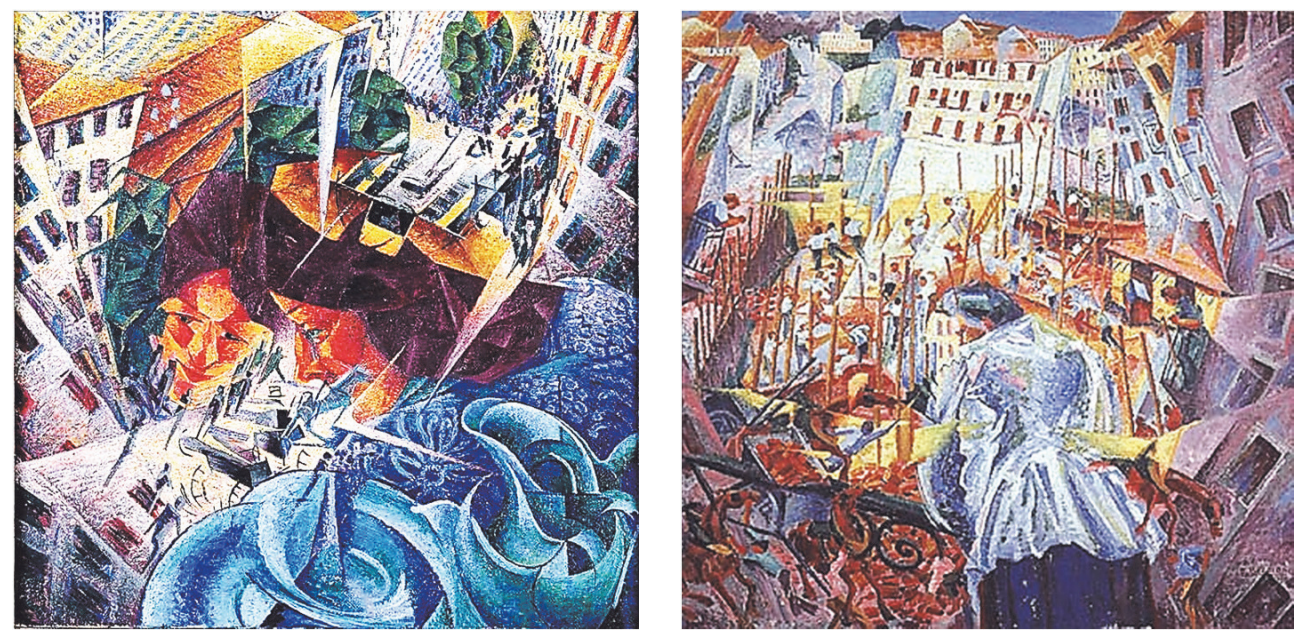

Figura 6. Boccioni, Visioni simultanee (1911) y La strada entra nella casa (1911).

La escritora, con una metáfora recurrente en su obra, describe las ventanas de los edificios londinenses como ojos, abiertos o tapados, sobre la ciudad. En la visión antropomórfica de los edificios solo las puertas permiten el contacto con la realidad 5 .

En línea con esa metáfora, tal vez los muros de ese edificio serían, en Gadda, aquel tejido epitelial que protege nuestra compleja fisiología: una ilusión consustancial a nuestra cognición. Véase Tutone (2017) y Bertoni (2001). 
Volvamos al incendio de la calle Keplero: las llamas sacan forzosamente a los inquilinos a la calle, rompen la ilusión de protección individual. El tono irónico sugiere, según Godioli (2011), la idea de que el desastroso accidente sea en realidad un castigo:

Alla base del riso gaddiano è il rancore di un soggetto umiliato dall'idiozia collettiva: creare una "personalità" che esprime questo senso di accerchiamento impedirebbe ogni slancio comunicativo, almeno nei termini che Gadda eredita dal romanzo ottocentesco; viceversa simulare una voce d'autore più affabile significa tradire la natura auténtica del riso. [...] L'Incendio rimuove il problema all'origine, celando la figura dell'autore: nemmeno una parola del testo può attribuirsi con certezza a una personalità autoriale definita, anzi il lavoro variantistico mira proprio ad eliminare ogni intervento diretto (Godioli 2011: 121).

El narrador, observa por lo tanto el estudioso, es parte de la vox populi y se confunde entre las historias o, mejor dicho, las versiones de la historia: una sátira sin yo. El cuchicheo de fondo - y volvemos a pensar en los canturreos que se propagan por las calles de Dublín (Joyce) y de Londres (Eliot) — es otra banda sonora de la metrópoli.

Visto de este modo, como un fuego-castigo que aniquila el espacio privado, podemos repensarlo, además, en términos de una tan benéfica como irónica purga de la estupidez colectiva que construye mil historias para obviar la verdad. De nuevo Godioli (2011: 179) cita un fragmento de El hombre sin atributos (1930-1942) de Robert Musil, en el que es evidente la separación, por medio del filtro de la ironía, del protagonista, Ulrich, de la simpleza colectiva:

[Ulrich] ripagava il suo secolo col definire volgare stupidità l'origine delle misteriose alterazioni che costituivano la malattia, distruggendo il genio. Né l'intendeva affatto in un senso offensivo. Infatti se di dentro la stupidità non assomigliasse straordinariamente all'influenza, se di fuori non si potesse scambiare per progresso, genio, speranza, perfezionamento, nessuno vorrebbe essere stupido e la stupidità non esisterebbe. $\mathrm{O}$ almeno sarebbe molto facile combatterla. Purtroppo invece essa ha qualcosa di singolarmente simpatico e naturale (Musil 2014: 77).

Musil habla de la estupidez en términos de una enfermedad, algo parecido a una gripe que aflige el sentido de la realidad, pero con la que, sin embargo, es fácil convivir sin darse cuenta. Pues bien, las llamas del número 14, en el relato de Gadda, provocan más evacuación de fluidos corporales, aparte de las lágrimas, a los desafortunados inquilinos; como si el peligro ofreciera a sus víctimas un atisbo de lucidez quebrantando las barreras de los ilusorios cuerpos individuales. Es el caso del viejo Zavattari, antes de que el fuego le alcanzara:

Il respiro breve che pareva scorrere su biglie di muco, coccolando con l'amorevolezza d'una mammina giovine quel suo catarro sommesso di catacomba, una colla che barbugliava, a lente bolle, in un pignattone dimenticato sul fuoco (Gadda 2011: 111).

La flema llega a la ebullición con las llamas, antes de que los bomberos rescaten a un Zavattari obnubilado y torpe por el vino: 
Non gli riuscì se non di rovesciare il fiasco del Barletta, semivuoto e imbecillito anche lui; e gli si erano invece spalancate tutt'a un tratto le cataratte dei bronchi e allentati, nel contempo, i più valorosi anelli inibitivi dello sfinctere anale, sicché fra urti di tosse terribili, mentre un fumo acre, nerissimo, gli principiò a filtrare in casa dalla toppa della serratura e da sotto l'uscio, nello spavento e nella congestione improvvisa, preso dall'orrore della solitudine e del sentirsi le gambe così di pasta frolla proprio nel momento del maggior bisogno, finì, anzitutto, con l'andar di corpo issofatto dentro la veste notturna: a piena carica: e poi per estromettere dalle voragini polmonari tanta di quella buona roba, che son sicuro che non ce la farebbe di certo neanche il mar di Taranto, con tutte le sue ostriche, a poterne pescar fuori di compagne (Gadda 2011: 112).

Asimismo, y para volver a la ciudad, aparece en el texto otro líquido en ebullición por efecto de las llamas: el gorgonzola, ese queso tan aborrecido por Gadda, que se derrite por el calor, y cuya denominación de origen procede de una pequeña ciudad muy cerca de Milán.

«L'incendio», dissero poi tutti, «è una delle cose più terribili che ci sia». Ed è vero: fra la generosità e la perplessità de' pompieri d'oro: fra cataratte d'acqua potabile sopra le ottomane pisciose e verdi, ma stavolta minacciate da un ben brutto rosso, e, sopra i cifoni e i credenzoni, custodi magari d'un mezz'etto di gorgonzola sudato, ma leccati già dalla fiamma come il capriolo dal pitone (Gadda 2011: 104).

La estructura del relato se moldea más en el perímetro urbano, constituido por la arquitectura del edificio en llamas y las calles en las que está alojado, que en los personajes, entre cuyas voces se posiciona el narrador. El avance vertical del incendio descubre al lector los personajes que se multiplican al igual que las llamas; no nos sorprende que, para describir la repetida reproducción del fuego, Gadda use la imagen de la mórula ${ }^{6}$, que en biología indica el óvulo fecundado que en el periodo de segmentación tiene el aspecto de una mora. Hay un proliferar de personajes y, paralelamente, de historias relatadas por otras voces entre las que se pierde la del narrador, que a su vez confunde el recuerdo con sus versiones y a menudo se corrige y vuelve sobre su historia. Ese dispositivo de proliferación constituye en sí la trama del relato y hace que nos preguntemos si no será el narrador un transeúnte espectador del drama. No hay épica ni tragedia y a los personajes se les niega cualquier redención. Observa Donnarumma (2006: 109-110): «Il pathos si sbilancia dall'evento al suo racconto [...] ma la parola letteraria spezza l'illusione del monolinguismo», que implicaría una coincidencia con el mundo de los personajes.

Decíamos que es como si el edificio de la calle Keplero, bajo el microscopio que nos revela su entramado interior hecho de historias que se reproducen en otras historias, fuera él mismo un nudo gaddiano visto tan de cerca que solo lo podemos percibir por segmentos. La enumeración podría ser, entonces, una visión desde dentro de la maraña, un zoom que no nos permite poner los elementos en relación los unos con

6 Entre las líneas 15-20 del relato se lee: «Il fuoco non poté fare a meno di liberare anche le sue proprie spaventose faville, tanto attese!, e lingue, a tratti subitanei, serpigne e rosse, celerissime nel manifestarsi e svanire, con tortiglioni neri di fumo, questo però pecioso e crasso come d'un arrosto infernale, e libidinoso solo di morularsi a globi e riglobi o intrefolarsi come un pitone nero su di se stesso, uscito dal profondo e dal sottoterra tra sinistri barbagli». 
los otros; todo se pierde, personajes e historias, al estallar el nudo por el incendio. La explosión de un punto en el entramado urbano muestra sus efectos, que se propagan por las calles aledañas hasta aplacarse engullidos por el caótico entrecruzamiento de las calles, digeridos por las tripas de Milán.

Kepler participa también en la construcción narrativa con la primera de sus tres leyes para describir el movimiento de los planetas, según la cual los planetas tienen movimientos elípticos alrededor del Sol, estando este situado en uno de los dos focos que contiene la elipse. Uno de los focos sería el edificio, alrededor del cual orbitan las historias y las calles, mientras que el otro tal vez sería la sospecha de la verdad que atrae, deformándola, nuestra ficticia visión de la realidad. Especularmente, nuestras órbitas alrededor de la verdad siempre están determinadas por otro foco: el dato real. En esos rodeos se pierde la confianza en nuestra supuesta objetividad y en poder llegar a una verdad última. La visión de la calle Keplero en llamas y el incendio de la calle Boltraffio podrían ser los dos focos de la órbita elíptica de la escritura que nunca consigue expresar directamente la verdad, puesto que el movimiento que nos lleva a ella está distorsionado por la complicada y falaz percepción de la realidad: el objeto del segundo foco.

Finalmente, si volvemos a pensar en términos de montaje cinematográfico, la referencia obligada es El hombre de la cámara (1929) de Dziga Vertov, donde otra metrópoli, Moscú, se abre ante el ojo de un operador de cámara que, desde el amanecer y a lo largo todo un día, recopila cuadros de las calles, con sus objetos y su gente, llegando a grabar fotogramas con imágenes difícilmente detectables para la vista humana (v. Figura 7). La cámara, que permite afortunados encuadres, cobra vida y ella sola busca su iconografía. El operador pasa a formar parte del documental, al mismo nivel que el resto de personajes. Seguidamente, el aparato filma el teatro Bolshoi, que al principio de la película nos mostraba a su público llenando la sala, hacerse añicos con un impresionante efecto óptico. 

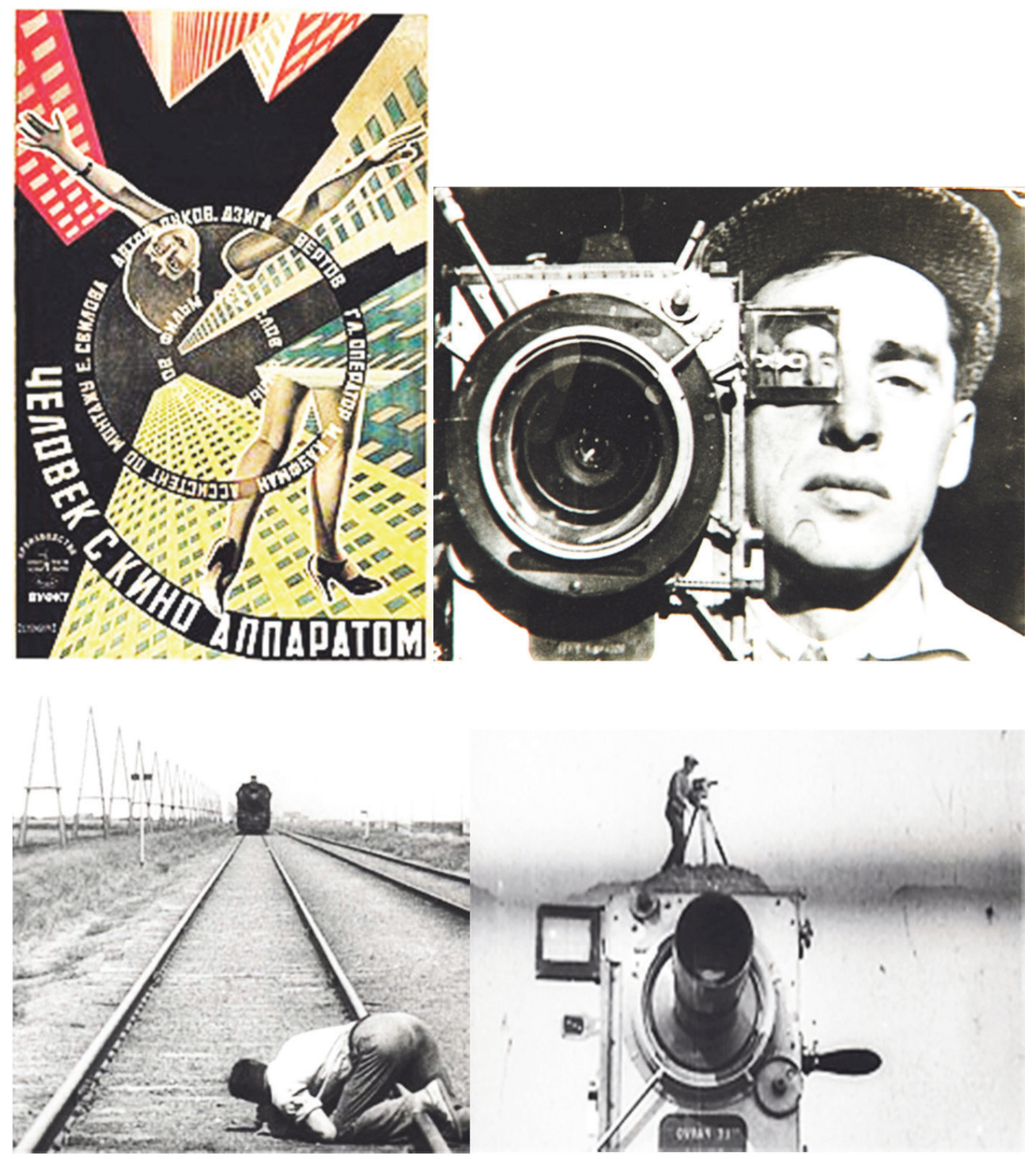

Figura 7. El cartel original de El hombre de la cámara (1929) y algunas imágenes de la famosa película.

Un filtro, la cámara o la escritura, que incorpora al operador-narrador. Imágenes que construyen una trama cuyo valor de verdad no es mediado por el narrador. Un argumento relatado siguiendo su propia expansión. Una metrópoli modernista:

Sicché l'autolettiga della Croce Verde, al quinto viaggio, si può dire che non era arrivata ancora alla guardia medica di via Paolo Sarpi, che già l'avevano fatta voltare indietro di volata verso l'obitorio della clinica universitaria, là in fondo alla città degli studi di dietro del nuovo Politecnico, macché in via Botticelli! più in là, 
più in là! in via Giuseppe Trotti, sì, bravi, ma passato anche via Celoria, però, passato via Mangiagalli, e poi via Polli, via Giacinto Gallina, al di là di Pier Gaetano Ceradini, di Pier Paolo Motta, a casa del diavolo (Gadda 2011: 113).

La ambulancia a toda velocidad, antes hacia el hospital y luego hacia el cementerio, recorre una elipsis en el mapa del centro de Milán cuyos focos podrían ser la Estación de trenes en la Plaza Duca d'Aosta, símbolo de la modernidad, y la Basílica de San Ambrogio, símbolo de la memoria histórica y de la transcendencia (v. Figura 8).

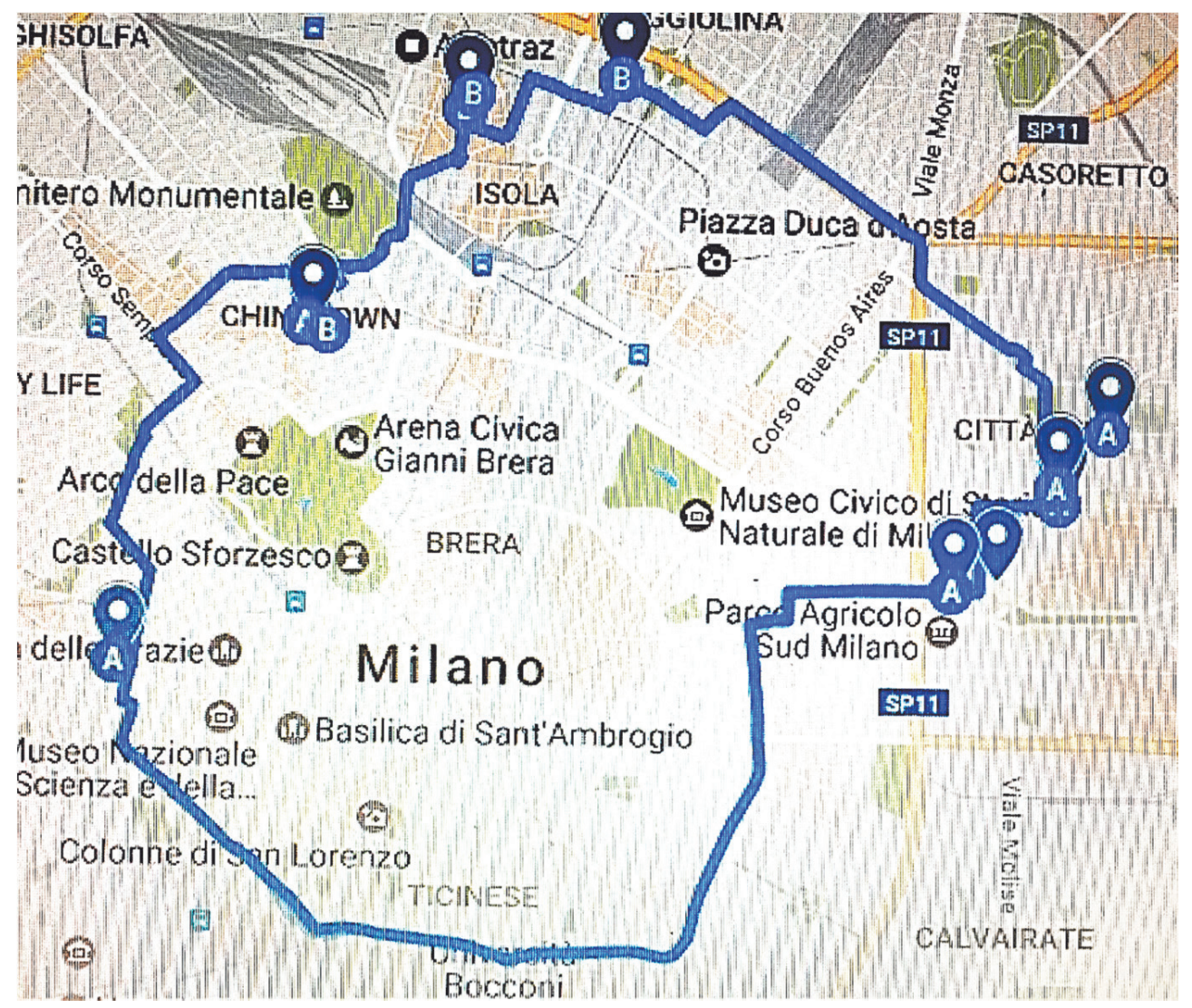

Figura 8. Imagen de Google Maps del centro de Milán en la que se ha marcado el desplazamiento de la ambulancia por las calles indicadas en el relato. Como puede apreciarse el recorrido recuerda a una elipsis.

\section{Riferimenti bibliografici}

Bertoni, Manuela (2001): La verità sospetta. Gadda e l'invenzione della realtà, Turín, Einaudi.

Cenati, Giuliano (2010): Disegni, bizze e fulmini, Pisa, ETS. 
Cianci, Giovanni (1991): Modernismo/Modernismi. Dall'avanguardia storica agli anni trenta e oltre, Milán, Principato.

Donarumma, Raffaele (2006): Gadda modernista, Pisa, ETS.

Eliot, Thomas Stearns (2000): The Waste Land, Nueva York, Norton.

Gadda, Carlo Emilio (2011): Accoppiamenti giudiziosi, Milán, Adelphi.

Godioli, Alberto (2011): «La scemenza del mondo». Riso e romanzo nel primo Gadda, Pisa, ETS.

James, Henry (2015): En la jaula, traducción de G. Moral Bartolomé, Barcelona, Alba.

Joyce, James. (2013): Ulisse, traducción de Gianni Celati, Turín, Einaudi.

Sarina, Andrea (2001): «L'incendio di via Keplero. «Studio 128» e "racconto inedito" di Carlo Emilio Gadda», The Edinburgh Journal of Gadda Studies, Monographs, 1, https:// www.gadda.ed.ac.uk/Pages/journal/monographs/sarina/sarina1.php.

Villa, Luisa (1991): «La città di Henry James», en G. Cianci (coord.), Modernismo / Modernismi. Dall'avanguardia storica agli anni trenta e oltre, Milán, Principato, pp. 481-487.

Woolf, Virginia (2013): Una stanza tutta per sé, traducción de L. Bacchi Wilcock, Milán, Feltrinelli. 